\title{
Study of antioxidant activity of liposomal forms of quercetin and curcumin in ischemic heart disease
}

\author{
DARIA PYLYPenKo $^{1}{ }^{*}$, Tatiana GoRbaCh ${ }^{1}$, YURIY KRASNOPOLSKY ${ }^{1}$ \\ ${ }^{1}$ National Technical University Kharkiv Polytechnic Institute, Kharkiv, Ukraine
}

\begin{abstract}
Quercetin and curcumin are plant polyphenolic antioxidants with proven pharmacological efficacy. Their use is, however, limited due to low bioavailability and oral administration route. The encapsulation of lipophilic compounds in liposomes enables to increase their bioavailability and to create an injectable form. The present study aimed to comparatively investigate the antioxidant activity of a complex liposomal preparation containing two lipophilic antioxidants (quercetin and curcumin) and their monopreparations in liposomal forms. This study was conducted on Wistar line rats with experimental model of ischemic heart disease. Oxidative stress markers such as total antioxidant activity, malondialdehyde, and peroxidized proteins were analyzed in blood serum and cardiac tissue. Ischemic heart disease is accompanied with lipid peroxidation and changes in the activity of the antioxidant system. The obtained results demonstrated the antioxidant activity of monopreparations of curcumin and quercetin and their complex in liposomal forms. Quercetin and curcumin showed different antioxidant activities in terms of oxidative stress markers. The complex of the two antioxidants showed the synergistic effect of their lipophilic compounds in liposomal forms, which led to the normalization of test parameters according to the level of the control sample.
\end{abstract}

Key words: curcumin, antioxidant, quercetin, liposomes, oxidative stress markers

\section{Introduction}

Lipid peroxidation of biological membranes accompanies many diseases in cardiology, oncology, pulmonology, ophthalmology, etc. (Middleton et al., 2000; Pavlova, 2016). Antioxidants (AOs) of natural origin such as quercetin (Quer) (Ozgen et al., 2016; Xu et al., 2019), curcumin (Cur) (Liu et al., 2017; Rachmani et al., 2018), vitamin $\mathrm{E}$ (Di Vincenzo et al., 2019), and coenzyme $\mathrm{Q}_{10}$ (Tiano et al., 2007; Liu et al., 2016) may be effective for treating these pathologies. The high lipophilicity of these compounds, however, impedes their use as injectable preparations. It is believed that to increase the low bioavailability of lipophilic AOs, they should be used in liposomal (LS) forms. Several studies have been conducted for creating LS forms of lipophilic AOs (Alexopoulou et al., 2006; Ranjan et al., 2013; Shakhmaiev et al., 2015; Shvets et al., 2016; Pylypenko et al., 2019b). These studies followed two directions: the creation and study of LS forms of individual active pharmaceutical ingre- dients (APIs) (Shakhmaiev et al., 2015; Ng et al., 2018; Bavacad et al., 2019) and their complexes (Chavesa et al., 2018; Esteban et al., 2018; Pylypenko et al., 2019a). The pharmacological activity of natural bioflavonoids, in particular Cur and Quer, has been widely studied (Lakhanpal and Rai, 2008; Slesarchuk, 2014; Liu et al., 2015; Liu et al., 2017; Dong et al., 2018; Small et al., 2018); however, these compounds are plant lipophilic antioxidants and their use is limited due to extremely low bioavailability (Zhang et al., 2011; Riva et al., 2019).

Quer is a well-known exogenous AO that blocks the processes of chain reactions of free radical oxidation, thus preventing excessive oxidation of lipids, proteins, and nucleic acids and protecting cell membranes from damage by oxidants - Figure 1 (Middleton et al., 2000; Nakusov, 2010). Quer has angioprotective, AO, antiinflammatory, wound healing, and antiviral effects (Lakhanpal and Rai, 2008; Ozgen et al., 2016; Dong et al., 2018; Xu et al., 2019). Currently, the world's first LS

\footnotetext{
* Corresponding author: National Technical University Kharkiv Polytechnic Institute, Kharkiv, Ukraine; e-mail: pdmforwork@gmail.com
} 
<smiles>O=c1c(O)c(-c2ccc(O)c(O)c2)oc2cc(O)cc(O)c12</smiles>

Fig. 1. Structure of quercetin

form of Quer ("Lipoflavon," Biolik, Ukraine) is used in clinical practice, for example, in cardiology, oncology, ophthalmology, type 1 and type 2 diabetes, psoriasis, pulmonology, renal failure, nephrotoxicity, and dentistry (Pasyechnikova et al., 2005; Ivanova and Yarosheva, 2008; Antipova et al., 2009; Belyaev, 2010; Asmolov et al., 2011; Ryabokon et al., 2011) .<smiles>COc1cc(/C=C/C(=O)CC(=O)/C=C/c2ccc(O)c(OC)c2)ccc1O</smiles>

Fig. 2. Structure of curcumin

Cur is a pleiotropic compound that shows a wide spectrum of biological activities in an organism and exhibits AO, anti-inflammatory, and antitumor properties (Fig. 2) (Shimatsu et al., 2012; Alrawaiq and Abdullah, 2014). Extensive evidence on the pharmacological activity of Cur in oncology, ophthalmology, cardiology, and other pathologies has been accumulated (Cheng et al., 2001; Shimatsu et al., 2012; Mosovska et al., 2016; Liu et al., 2017; Pylypenko et al., 2018; Rachmani et al., 2018; Small et al., 2018). Long-term global data on the oral administration of Cur have confirmed its safety and efficacy (Cheng et al., 2001; Sanmukhani et al., 2014; Small et al., 2018). Although studies aimed at creating Cur nanoforms based on liposomal, polymer, or metal nanoparticles have been recently successfully completed (Feng et al., 2017; Ng et al., 2018), there is currently no commercial injectable preparation of Cur available in the market.

Considering the possibility of the effect of AOs on different components of the AO system, studies have focused on the complexes of these compounds with various APIs and their protective functions. Chaves et al. (2018) coencapsulated Cur and vitamin D3 in a multillamellar LS and showed that LS vesicles were stable throughout 42 days of storage and the efficiency of encapsulation of Cur and vitamin D3 was at least 89.6\% and $88.3 \%$, respectively. The effectiveness of using LS form of Quer obtained from plant extract for treating eye injury in rabbits was evaluated (Sotnikova et al., 2018). A comparative study of levodopa in a complex LS form containing Cur in the membrane bilayer and ascorbic acid and superoxide dismutase in the aqueous phase (Esteban et al., 2018) was carried out, and it was found that the co-loaded liposomes ensured the chemical stabilization of levodopa. The liposomes also exhibited a potential radical scavenging activity, mainly due to ascorbic acid. The effect of the complex LS preparation containing Quer and coenzyme Q10 was studied in rats with ischemic heart disease, and the synergistic effect of these two AOs has been proved (Pylypenko et al., 2019a). Another study of particular interest demonstrated a high AO effect of the LS complex of two polyphenols: Quer and a gallate-epigallocatechin isolated from green tea. The authors of this study prepared a stable LS form with mean size particle of $111.10 \pm 0.52 \mathrm{~nm}$ and with at least $60 \%$ efficiency of encapsulation, and a synergistic effect of these two compounds in LS form was observed in 2,2-diphenyl-1-picrylhydrazyl assay (Chen et al., 2019).

A literature review showed that no studies have been conducted on the use of Quer and Cur complex in LS form for AO activity. The present study therefore aimed to investigate the $\mathrm{AO}$ activity of complex LS preparation containing two lipophilic AOs (Quer and Cur) tested on the rat model of ischemic heart disease (IHD).

\section{Materials and methods}

\section{Materials}

Quer $\left(\mathrm{C}_{15} \mathrm{H}_{10} \mathrm{O}_{7}\right)$ was manufactured by PVP Sociedate Anonima (Brazil), and a highly purified curcuminoid complex was obtained according to the protocol of Pylypenko and Krasnopolsky (2019). In the product used, curcuminoids were represented by diferulomethane (Cur I $-\mathrm{C}_{21} \mathrm{H}_{20} \mathrm{O}_{8}$ ) in the amount of at least 70-75\%, demethoxycurcumin (Cur II - $\mathrm{C}_{20} \mathrm{H}_{18} \mathrm{O}_{5}$ ), and bisdemethoxycurcumin (Cur III $-\mathrm{C}_{19} \mathrm{H}_{16} \mathrm{O}_{4}$ ) - the last two fractions in the amount of $25-30 \%$. On the basis of literature reports that the minor components of cur- 
cuminoids might exhibit $\mathrm{AO}$ and anti-inflammatory properties, we used an API containing three curcuminoids to prepare the LS form. To prepare LS, the following phospholipids were purchased from Lipoid, Germany: phosphatidylcholine (PC) from egg yolk and dipalmitoylphosphatidylglycerol (DPPG); lactose from Sigma Aldrich, USA; and PBS. The standards of PC and lysophosphatidylcholine (lysoPC) manufactured by Sigma Aldrich were used for analytical studies.

\section{Preparation of Liposomes}

LS forms of Quer and Cur were prepared using a previously developed technological platform (Grygorieva et al., 2017; Pylypenko et al., 2019b).

\section{Analytical studies}

Chromatographic (HPLC and TLC) and spectrophotometric methods were used to qualitatively and quantitatively analyze the content of Quer and Cur. The analytical studies were performed according to the protocols of the State Pharmacopoeia of Ukraine (2015).

High-performance liquid chromatography (HPLC) analysis of Cur was performed using Shimadzu Prominence LC-20 chromatograph with an SPD-M20A diode array detector, a Shim-pack GISS C18 column $(5 \mu \mathrm{m}$, $250 \times 4.6 \mathrm{~mm}$ ), a CTO-20AC column thermostat, column temperature of $30^{\circ} \mathrm{C}$; and a mobile phase of water: acetonitrile (54:46), adjusted with glacial acetic acid to $\mathrm{pH}$ $3.0 \pm 0.05$. The detection was performed at the wavelength of $427 \mathrm{~nm}$. Sample volumes were 2-10 $\mu$ l.

HPLC analysis of Quer was performed in the isocratic mode on a Shimadzu LC 20 chromatograph with a chromatographic column $(250 \times 4.6 \mathrm{~mm})$ filled with $\mathrm{L} 1$ sorbent with particle size of $5 \mu \mathrm{m}$ (Waters Xbridge) and a mobile phase of methanol:water:phosphoric acid $(100: 100: 1)$. The flow rate of the mobile phase was $1 \mathrm{ml} / \mathrm{min}$, and the detection was performed at the wavelength of $255 \mathrm{~nm}$, with column temperature of $30^{\circ} \mathrm{C}$. The sample volume was $20 \mu \mathrm{l}$. The average retention time of Quer was $38 \pm 0.5 \mathrm{~min}$, which corresponded to the retention time of the standard Quer sample. Impurities in Quer (kaempferol and isoramnetin) were not higher than $2.0 \%$, which corresponded to the limits specified by the manufacturer.

Quer and Cur were quantified spectrophotometrically at 375 and $540 \mathrm{~nm}$, respectively. Thin layer chromatography (TLC) analysis was performed using silica gel 60 aluminum-backed TLC plates (Sigma-Aldrich). The mobile phases were chloroform-methanol $(98: 2)$ for Cur and chloroform-methanol-water $(65: 25: 4)$ for phospholipids.

The presence of residual solvents in LS was determined by gas chromatography on a Shimadzu GC2014 ATF/SPL gas chromatograph with an AOS-6000 universal autosampler and an SH-Rtx-624 MS column ( $30 \mathrm{~m}, 0.32 \mathrm{~mm}, 5 \mu \mathrm{m}$ ). The following conditions were used: input method: Static Head Space; sample temperature: $100^{\circ} \mathrm{C}$ (the sample was incubated with shaking for $15 \mathrm{~min}$ before the input); syringe temperature: $120^{\circ} \mathrm{C}$; injector temperature: $200^{\circ} \mathrm{C}$; detector temperature: $300^{\circ} \mathrm{C}$; carrier gas: helium; gas velocity: $35 \mathrm{~cm} / \mathrm{s}$; flow rate: $2.16 \mathrm{ml} / \mathrm{min}$; solvent: DMF; volume of the injection: $0.5 \mathrm{ml}$.

The size of LS was measured on the Malvern Zetasizer Nano ZS nanosizer (UK) using a semiconductor laser at $375 \mathrm{~nm}$ wavelength and $30^{\circ} \mathrm{C}$. The oxidation index was determined by UV spectrophotometry at the wavelength of 210 and $233 \mathrm{~nm}$. The suitability of the chromatographic systems was determined in accordance with the guidelines of State Pharmacopoeia of Ukraine (2015).

\section{Pharmacological Studies}

The experimental part of the studies was performed at the Biochemistry Department of Kharkiv National Medical University, Ukraine. The study was conducted on 30 Wistar line rats weighing 150-180 g, which were kept in standard vivarium conditions. The following groups of animals were used: 1$)$ control group $(n=6)$; $2)$ rats with experimental IHD $(n=6)$; 3$)$ rats with experimental IHD treated with LS form of Quer $(n=6)$; 4) rats with experimental IHD treated with LS form of Cur $(n=6)$; and 5) rats with experimental IHD treated with LS form of Quer and Cur complex $(n=6)$.

IHD was stimulated in IHD model rats following the procedure of Gaman et al. (2011): $0.1 \mathrm{ml}$ of $0.1 \%$ adrenaline solution and $1 \mathrm{ml}$ of $2.5 \%$ hydrocortisone acetate suspension were subcutaneously administered daily for 7 days into IHD model rats. After simulating the IHD, the test samples were intravenously administered daily for 5 days at the dose of $10 \mathrm{mg} / \mathrm{kg}$.

Blood samples were obtained from the tail vein. Cardiac tissue samples were obtained by cardiac puncture in anesthetized rats using the following procedure: the 
heart sample was washed in ice-cold $0.9 \% \mathrm{NaCl}$ solution, weighed, and homogenized with three volumes of the solution. The homogenate was filtered and precipitated at $10000 \mathrm{~g}$ for $10 \mathrm{~min}$. The supernatant was used in the study.

The animals were kept under standard conditions in accordance with the regulations of the National Research Council (2010). All procedures were conducted in accordance with the European Convention for the Protection of Vertebrate Animals used for Experimental and Other Scientific Purposes (Strasbourg, 1986), and the experimental protocol was approved by the local animal ethics committee.

\section{Determination of peroxidation and $\mathrm{AO}$ protection products}

Malondialdehyde (MDA) concentration was determined by the thiobarbituric acid reaction method, and the absorbance of the colored complex was measured spectrophotometrically at $532 \mathrm{~nm}$ (Deryugina et al., 2010). Conjugated dienes (CDs) were extracted with the heptane-isopropanol mixture, and the amount of CDs was determined spectrophotometrically at $233 \mathrm{~nm}$ (Deryugina et al., 2010). The activity of superoxide dismutase (SOD) was determined spectrophotometrically at $450 \mathrm{~nm}$. The method is based on the inhibition of nitroblue tetrazolium reduction in a nonenzymatic system of phenazine methosulfate and NADH (Matyushin et al., 1991). The catalase activity was determined spectrophotometrically; the method is based on the ability of hydrogen peroxide to form a stable colored complex with ammonium molybdate with the maximum absorbance at $410 \mathrm{~nm}$ (Korolyuk et al., 1988). Determination of the SH-group concentration is based on the reaction of the sulfhydryl group with 5,5-dithiobis-(2nitrobenzoic acid), which results in the formation of equimolar amounts of yellow-colored thionitrophenyl anion with the maximum absorbance at $412 \mathrm{~nm}$ (Deryugina et al., 2010). ATP concentration was determined based on the principle of glucose phosphorylation in the presence of hexoinase. The amount of ATP is equimolar to NADPH formed in the glucose-6-phosphate dehydrogenase reaction (Eschenko et al., 1982). The protein peroxidation (PP) level was determined based on the reaction of carbonyl groups with 2,4-dinitrophenylhydrazine where protein-bound 2,4-dinitrophenylhydrazone is formed, which can be detected spectrophotometrically at $370 \mathrm{~nm}$ (Dubinina et al., 1995). The total antioxidant activity (TAA) in the blood serum was determined spectrophotometrically as a degree of inhibition of LOPs (thiobarbituric acid reactive substances) production in yolk lipoproteins. Lipid peroxidation in the yolk lipoprotein suspension was induced by the addition of $\mathrm{FeSO}_{4}$ following the procedure of Kibanov et al. (1988).

\section{Statistical analysis}

The data are expressed as mean \pm SEM. Statistical significance of the differences between the groups was analyzed using Student's t-test in accordance with the State Pharmacopoeia of Ukraine (2015).

\section{Results}

Table 1 shows the characteristics of the obtained monopreparations of Quer and Cur in LS forms and the LS preparation containing Quer and Cur complex. The particle size of the LS was 130-200 nm before lyophilization and $200-300 \mathrm{~nm}$ after lyophilization; this implies that it was suitable for intravenous administration. The efficiency of encapsulation of Quer and Cur into LS was at least 90 and $85 \%$, respectively. All the preparations were yellow colored with different color intensities; $\mathrm{pH}$ values were between 6.6 and 7.2 , and the time of emulsification of lyophilized LS preparations was maximum $5 \mathrm{~min}$. Lyophilized preparations were stable for at least 12 months and contained a maximum of $5 \%$ water.

The influence of Quer and Cur monopreparations in the LS form and the LS preparation containing Quer and Cur complex on oxidative stress markers (concentrations of MDA, CDs, total antioxidant activity, SOD, catalase, SH-groups, and ATP) was analyzed in the IHD model rats, and the results were compared with those obtained for control animals. Table 2 shows the impact of LS preparations on oxidative stress markers in the blood serum of experimental animals.

An increase in the content of MDA and CDs by 180.9 and $73.1 \%$, respectively, was observed in the blood serum of rats with IHD as compared to those in control animals $(P<0.001)$. The administration of monopreparations to the animals reduced the content of MDA and CDs by 56.7 and $33.0 \%$, respectively, in the blood serum of the Quer group and by 30.5 and $12.6 \%$, respectively, in the blood serum of the Cur group as compared to those in animals with IHD $(P<0.001)$. The administra- 
Table 1. The characterization of complex LS preparation Quer and Cur and their monopreparations

\begin{tabular}{l|c|c|c|c|c|c|c}
\hline $\begin{array}{c}\text { Name } \\
\text { of sample }\end{array}$ & $\begin{array}{c}\text { API content } \\
{[\mathrm{mg} / \mathrm{ml}]}\end{array}$ & $\begin{array}{c}\text { PC content } \\
{[\mathrm{mg} / \mathrm{ml}]}\end{array}$ & $\begin{array}{c}\text { DPPG } \\
\text { content } \\
{[\mathrm{mg} / \mathrm{ml}]}\end{array}$ & $\begin{array}{c}\text { Lactose } \\
\text { content } \\
{[\mathrm{mg} / \mathrm{ml}]}\end{array}$ & $\begin{array}{c}\text { Encapsulation } \\
\text { of API into LS } \\
{[\%]}\end{array}$ & $\begin{array}{c}\text { LS size before } \\
\text { lyophilisation } \\
{[\mathrm{nm}]}\end{array}$ & $\begin{array}{c}\text { LS size after } \\
\text { lyophilisation } \\
{[\mathrm{nm}]}\end{array}$ \\
\hline LS-Cur & 0.785 & 28.0 & 2.8 & 42.0 & at least 85 & $130-150$ & $200-280$ \\
\hline LS-Quer & 0.75 & 27.5 & - & 42.0 & at least 90 & $160-180$ & $180-220$ \\
\hline LS-Cur + Quer & $0.38 / 0.35$ & 27.5 & 1.4 & 42.0 & $\begin{array}{c}\text { at least } 85 \\
\text { and at least } 90, \\
\text { respectively }\end{array}$ & $160-200$ & $240-300$ \\
\hline
\end{tabular}

Table 2. Results of the study of the AA using the IHD model: rat blood serum, $10 \mathrm{mg} / \mathrm{kg}$ daily, 5 injections

\begin{tabular}{l|c|c|c|c|c|c|c}
\hline \multicolumn{1}{c|}{ Indices } & $\begin{array}{c}\mathrm{MDA} \\
{[\mu \mathrm{mol} / \mathrm{l}]}\end{array}$ & $\begin{array}{c}\mathrm{CD} \\
{[\mu \mathrm{mol} / \mathrm{l}]}\end{array}$ & $\begin{array}{c}\text { SOD } \\
{[\mathrm{RU} / \mathrm{sec} / \mathrm{l}]}\end{array}$ & $\begin{array}{c}\text { Catalase } \\
{[\mu \mathrm{mol} / \mathrm{l}]}\end{array}$ & $\begin{array}{c}\text { SH Groups } \\
{[\mathrm{mmol} / \mathrm{l}]}\end{array}$ & $\begin{array}{c}\text { TAA } \\
{[\%]}\end{array}$ & $\begin{array}{c}\text { PP } \\
{[\mathrm{U} / \mathrm{mg} \mathrm{protein}]}\end{array}$ \\
\hline Control & $2.09 \pm 0.07$ & $51.33 \pm 0.65$ & $33.83 \pm 1.01$ & $20.62 \pm 0.37$ & $12.91 \pm 0.12$ & $52.32 \pm 0.64$ & $0.127 \pm 0.004$ \\
\hline IHD & $5.87 \pm 0.08$ & $88.87 \pm 0.38$ & $40.80 \pm 0.36$ & $27.68 \pm 0.29$ & $7.16 \pm 0.17$ & $31.18 \pm 0.47$ & $0.336 \pm 0.019$ \\
\hline IHD + Quer & $2.54 \pm 0.12$ & $59.53 \pm 0.62$ & $52.75 \pm 0.78$ & $38.77 \pm 0.34$ & $7.73 \pm 0.23$ & $57.04 \pm 0.42$ & $0.101 \pm 0.006$ \\
\hline IHD + Cur & $4.08 \pm 0.10$ & $77.69 \pm 0.71$ & $44.55 \pm 0.33$ & $32.54 \pm 0.39$ & $10.05 \pm 0.38$ & $47.48 \pm 0.50$ & $0.206 \pm 0.010$ \\
\hline IHD + Quer + Cur & $1.80 \pm 0.03$ & $47.83 \pm 0.32$ & $31.11 \pm 0.44$ & $19.22 \pm 0.26$ & $13.54 \pm 0.29$ & $49.54 \pm 0.37$ & $0.108 \pm 0.005$ \\
\hline
\end{tabular}

tion of the LS form of Quer and Cur complex reduced the amount of MDA and CDs by 68.9 and $46.2 \%$, respectively, as compared to those in animals with IHD $(P<0.001)$, which was almost at the level of the intact control (Table 2).

Regarding the total antioxidant activity, a decrease in activity by $40.4 \%$ was observed in the blood serum of rats with IHD as compared to that in control animals $(P<0.001)$. The administration of monopreparations increased the total antioxidant activity by 82.9 and $52.3 \%$ in the Quer and Cur groups, respectively, and the use of the LS form of Quer and Cur complex increased the total antioxidant activity by $59.0 \%$ as compared to that in animals with IHD $(P<0.001)$. Consequently, the use of Quer and Cur monopreparations as well as their complex in LS forms normalized the total antioxidant activity close to that of the intact control (Table 2).

The protein peroxidation level increased by $164.6 \%$ in animals with IHD as compared to that in the intact control $(P<0.001)$. The use of a complex LS preparation and the LS form of Quer monopreparation led to the normalization of the protein peroxidation level close to that of the intact control. The use of the LS form of Cur monopreparation showed an increase in the protein peroxidation level by $62.2 \%(P<0.01)$ as compared to that in the intact control (Table 2).
The content of SH-groups in the blood serum of animals with IHD decreased by $44.5 \%(P<0.001)$. In rat groups administered with Quer and Cur monopreparations, the level of SH-groups remained below the intact control by $40.1 \%(P<0.001)$ and $22.2 \%(P<0.01)$, respectively. Furthermore, the administration of the LS form of Quer and Cur complex normalized the content of SH-groups in the blood serum to the level of control animals (Table 2).

Similar trends were also observed in the content of oxidative stress markers in the heart muscle (Table 3). An increase in the content of MDA and CDs by 136 and $88.5 \%$, respectively, was observed in the cardiac tissue of rats with IHD as compared to those in the control animals $(P<0.001)$. The administration of monopreparations to animals decreased the content of MDA and CDs by 46.7 and $36.4 \%$, respectively, in the cardiac tissue of the Quer group $(P<0.001)$ and decreased the content of MDA and CDs by $24.5 \%(P<0.001)$ and $18.4 \%$ $(P<0.01)$, respectively, in the Cur group as compared to those in animals with IHD. The use of the LS forms of Quer and Cur complex reduced the amount of MDA and CDs by 52.1 and $49.0 \%$, respectively, as compared to those in animals with IHD $(P<0.001)$, which was almost at the level of the intact control (Table 3 ). 
Table 3. Results of the study of the AA using the IHD model: rat cardiac tissue, $10 \mathrm{mg} / \mathrm{kg}$ daily, 5 injections

\begin{tabular}{l|c|c|c|c|c}
\hline \multicolumn{1}{c|}{ Indices } & $\begin{array}{c}\text { MDA } \\
{[\mathrm{mmol} / \mathrm{g} \text { protein }]}\end{array}$ & $\begin{array}{c}\mathrm{CD} \\
{[\mathrm{mmol} / \mathrm{g} \text { protein }]}\end{array}$ & $\begin{array}{c}\text { SOD } \\
{[\text { RU/g protein }]}\end{array}$ & $\begin{array}{c}\text { Catalase } \\
{[\mu \mathrm{mol} / \mathrm{g} \text { protein }]}\end{array}$ & $\begin{array}{c}\text { ATP } \\
{[\mathrm{mmol} / \mathrm{g} \text { protein }]}\end{array}$ \\
\hline Control & $1.75 \pm 0.02$ & $15.27 \pm 0.39$ & $98.05 \pm 0.41$ & $24.68 \pm 0.28$ & $3.53 \pm 0.19$ \\
\hline IHD & $4.13 \pm 0.09$ & $28.78 \pm 0.64$ & $116.82 \pm 2.15$ & $31.28 \pm 0.43$ & $1.47 \pm 0.04$ \\
\hline IHD + Quer & $2.20 \pm 0.08$ & $18.31 \pm 0.22$ & $139.91 \pm 1.33$ & $44.26 \pm 0.50$ & $1.81 \pm 0.04$ \\
\hline IHD + Cur & $3.10 \pm 0.07$ & $23.49 \pm 0.72$ & $128.67 \pm 0.87$ & $34.91 \pm 0.49$ & $1.65 \pm 0.05$ \\
\hline IHD + Quer + Cur & $1.98 \pm 0.04$ & $14.69 \pm 0.21$ & $104.36 \pm 1.62$ & $27.57 \pm 0.65$ & $2.14 \pm 0.05$ \\
\hline
\end{tabular}

To study the changes in the enzymatic $\mathrm{AO}$ defense system, the levels of SOD and catalase were determined. An increase in the content of SOD and catalase by 20.6 and $34.3 \%$, respectively, was observed in the blood serum of rats with IHD as compared to those in the control animals $(P<0.01)$. The levels of SOD and catalase were similar to those of the intact control rat group administered with the LS form of Quer and Cur complex (Table 2). Similar trends were also observed in the cardiac tissue (Table 3). An increase in the content of SOD and catalase by 19.1 and $26.7 \%$, respectively, was observed in the cardiac tissue of rats with IHD as compared to those in control animals $(P<0.01)$. Treatment with the LS form of Quer and Cur complex reduced the amount of SOD and catalase by 10.6 and $11.2 \%$, respectively, as compared to those in animals with IHD $(P<0.05)$, which is almost at the level of the intact control (Table 3). In the rat groups administered with Quer and Cur, the monopreparations increased the levels of SOD and catalase even more than that in the rats with IHD in both blood serum and cardiac tissue.

The ATP level decreased by $58.4 \%$ in the cardiac tissue of rats with IHD as compared to those in control animals $(P<0.001)$. The administration of monopreparations increased the ATP level by 23.0 and $12.2 \%$ in the Quer and Cur groups, respectively, and the use of the LS form of Quer and Cur complex increased the ATP level by $45.5 \%$ as compared to that in animals with $\operatorname{IHD}(P<0.01)$. The concentrations of ATP in groups of LS preparations were lower than those of control animals, but the use of a complex preparation was more effective than the use of monopreparations of Quer and Cur (Table 3).

\section{Discussion}

Many cardiological diseases are accompanied with changes in the levels of several oxidative stress markers
(Middleton et al., 2000). Lipid peroxidation in the cardiac tissue leads to serious pathologies such as IHD, myocardial infarction, and arrhythmia (Rodrigo et al., 2013; Farías et al., 2017). Currently, various AOs with cardioprotective effect are being considered for the treatment of cardiac pathologies (Khalil and Sulaiman, 2010; Lopera et al., 2013; Rodrigo et al., 2013; Pavlova, 2017). Liposomes allow to create a water-soluble injectable form of lipophilic APIs and thus increase their bioavailability (Shvets et al., 2016). LS preparations with cardioprotective effect have been proposed for use in cardiology, for example, LS form of Coenzyme Q10 (Shakhmaiev et al., 2015), LS form of adenosine (Takahama et al., 2009), LS form of resveratrol and carvedilol (Alanazi et al., 2020), and LS form of Quer and Coenzyme Q10 (Pylypenko et al., 2019a).

A review of literature indicates that several studies have been conducted for obtaining monopreparations of LS lipophilic AOs (Cur or Quer) (Alexopoulou et al., 2006; Shaji and Iyer, 2012; Ranjan et al., 2013; Feng et al., 2017; Melnyk et al., 2018; Ng et al., 2018; Bavacad et al., 2019). However, the number of studies on complex LS forms is scarce (Ravichandiran et al., 2017; Sadeghi Ghadi et al., 2019). Nanoparticles containing Quer and Cur were prepared by the lipid film method with particle size of $261.8 \pm 2.1 \mathrm{~nm}$ (Ravichandiran et al., 2017) and 260 $\pm 6.58 \mathrm{~nm}$ (Sadeghi Ghadi et al., 2019) and with the efficiency of encapsulation of Cur and Quer of $98.85 \pm 0.55 \%$ and $93.13 \pm 1.22 \%$, respectively (Sadeghi Ghadi et al., 2019). Consequently, the physicochemical properties of our complex LS preparation was similar (particle size of LS preparations after lyophilization was 200-300 $\mathrm{nm}$ and the efficiency of encapsulation of Quer and Cur into LS was at least 90 and 85\%, respectively Table 1). Moreover, IHD is accompanied with lipid peroxidation and a change in the activity of the $\mathrm{AO}$ system 
(Pavlova, 2017), as confirmed by the results of our experiments (Table 2 and Table 3 ).

The obtained results demonstrate antioxidant activities of monopreparations of LS forms of Cur, Quer, and their complex. Moreover, the monopreparations of Quer and Cur exhibited different antioxidant activities when compared with each other. A study on the influence of Quer and Cur in LS form on the activities of several oxidative stress markers showed that Quer exhibited a higher antioxidant activity, in particular for MDA, CDs, and protein peroxidation; in other cases, Cur was more effective, for example, for SH-groups. However, the most effective reduction in the levels of all studied oxidative stress markers in the blood serum and cardiac tissue of rats with IHD was achieved using an LS preparation containing the complex of both Quer and Cur. Apparently, AO activity depends on both the amount of AOs (Quer and Cur) used and their mutual synergy.

Several authors have indicated the synergistic effect of the AO activity of Quer and Cur on the basis of increased total AO activity and reduced MDA and lipid hydroperoxide levels (Liu et al., 2015; Balakina et al., 2017; Ravichandiran et al., 2017; Sadeghi Ghadi et al., 2019). In addition, the membrane-protective properties of Quer and Cur contribute to the increase in the protective and adaptive potential of the rat body (Balakina et al., 2017). Liu et al (2015) administered Quer and Cur separately and in combination per os to mice with lung cancer. They found that the use of both bioflavonoids separately and in combination improved the body weight of mice and reduced lung weight. Importantly, the coadministration of Quer and Cur reduced the levels of MDA and reactive oxygen species more effectively (Liu et al., 2015), which might be because Quer and Cur have different mechanisms of $\mathrm{AO}$ activity and have a higher therapeutic effect when administered in combination. It is noteworthy that the doses used per os (40 to $200 \mathrm{mg} / \mathrm{kg}$ ) were significantly higher than those of Quer and Cur in LS form $(10 \mathrm{mg} / \mathrm{kg})$ that were administered in the present study. The encapsulation of lipophilic compounds into LS enables to increase their bioavailability and efficacy, and hence, it is possible to decrease the doses of APIs.

Detoxification of reactive oxygen species in cells is performed by both enzymatic and nonenzymatic systems, which constitute the AO defense system (Middleton et al., 2000). AOs decrease the level of free radicals by inhibiting the activities or expression of free radical generating enzymes or by promoting the activities and expression of antioxidant enzymes (Lü et al., 2010). The enzymatic system includes the following enzymes: SOD, catalase, glutathione peroxidases, and glutathione-regenerating enzyme (Middleton et al., 2000). SOD is one of the main enzymes of the $\mathrm{AO}$ system that are related to metal enzymes that catalyze the dismutation reaction of superoxide anion radicals to maintain their content in the cell at low levels and reduce the likelihood of formation of even more active singlet oxygen (Middleton et al., 2000; Nakusov, 2010). Catalase is a membrane-bound enzyme that is a major element involved in maintaining the intracellular concentration of reduced glutathione, which plays an important role in neutralizing free radicals (Middleton et al., 2000; Nakusov, 2010).

The data obtained in this study are consistent with the results available in the literature (Tiano et al., 2007; Gubareva et al., 2008; Nakusov, 2010; Orlova and Lazarchuk, 2010; Shakhmaiev et al., 2015). For example, Quer and dihydroquercetin drugs, which reduce the content of lipid oxidation products or inhibit their accumulation during the hypoxic action, increase the activity of AO enzymes by eliminating the peroxide metabolism products that inhibit them (Nakusov, 2010). As suggested by Nakusov (2010), it is also possible that flavonoids directly affect enzymes by interacting with amino acid radicals of the polypeptide chain, thereby changing the conformation of the protein molecule, which contributes to a change in the properties of the enzyme. This may be due to an increase in the SOD and catalase activity above the control level. Pavlova (2017) showed that 1-2 days after myocardial infarction in humans, the SOD level increased 2.1 times as compared to that in the control (healthy people); this may be associated with its compensatory allosteric activation in the conditions of hyperproduction of the superoxide anion radical that activates SOD and simultaneously inhibits catalase. In the subsequent 10-14 days, the SOD activity decreased; nevertheless, its content was 1.4 times higher than that of the control group (Pavlova, 2017). The authors showed an increase in the activity of SOD and catalase not only in patients with IHD but also in patients treated with AOs, which may be associated with the inhibition of the lipid peroxidation process. It has been established that strong AOs not only play a role in "trapping" free radicals, but they also increase the enzymatic activity of SOD (Middleton et al., 2000; Pavlova, 
2017). Other authors showed an increase in the activity of SOD and catalase in cardiac pathology (Agarkov et al., 2017; Romuk et al., 2019). Some authors indicated an increase in the activity of SOD in the heart of rats, which was observed while studying markers of oxidative stress in streptomycin model of type 2 diabetes (Agarkov et al., 2017) and in cases of severe chronic heart failure (Pavlova, 2016).

\section{Conclusions}

A comparative study of the antioxidant activities of Quer and Cur monopreparations in LS form and the LS preparation containing Quer and Cur complex was conducted on the IHD model in rats. The administration of the complex showed a synergistic antioxidant effect of two lipophilic compounds in LS form. Additionally, Quer showed higher activity than Cur in the monopreparations. A statistically significant decrease was observed in the level of lipid oxidation products and an increase in the activity of the antioxidant activity system on the IHD model in rats using an LS preparation containing Quer and Cur complex as compared to the LS form of monopreparations. Currently, the use of LS antioxidant drugs is a promising area for pharmacotherapy in cardiology. On the basis of our results, the complex LS preparation containing Quer and Cur may be used to prevent free radical oxidation in cells during IHD. Future studies will assess the dose-dependent effect and the development of an optimal pharmaceutical form.

\section{References}

Agarkov A.A., Popova T.N., Voronkova Y.R., Urazova V.R., Sinilo P.A., Chichay A.S. (2017) The activity of SOD and catalase in the heart of rats with streptomycin type 2 diabetes with the introduction of SQ1. Bull. Mod. Res. 10-11(13): 6-8.

Alanazi A., Fadda L., Alhusaini A., Ahmad R. (2020) Antioxidant, antiapoptotic, and antifibrotic effects of the combination of liposomal resveratrol and carvedilol against doxorubicin-induced cardiomyopathy in rats. J. Biochem. Mol. Toxicol. 15: e22492.

Alexopoulou E., Georgopoulos A., Kagkadis K.A., Demetzos C. (2006) Preparation and characterization of lyophilized liposomes with incorporated quercetin. J. Liposome Res. 16(1): 17-25.

Alrawaiq N.S., Abdullah A. (2014) A review of antioxidant polyphenol curcumin and its role in detoxification. Int. J. PharmTech Res. 6(1): 280-289.
Antipova S.V., Shepilov A.V., Ryabtseva O.D. (2009) $E_{X}$ perience of Lipoflavon application to prevention development of cardiac complications in patients with operable breast cancer treated with anthracyclines. Prob. Mod. Med. Sci. Educ. 2: 44-46.

Asmolov A.K., Rybak T.A., Baburina E.A., Gerasimova N.A. (2011) Usage of lipoflavon in the treatment of chronic obstructive pulmonary diseases. Bull. Acad. Stiinte Moldovei 4(32): 199-200.

Balakina A.S., Aksenov I.V., Trusov N.V., Guseva G.V., Avrenyeva L.I., Kravchenko L.V., Tutelyan V.A. (2017) The influence of separate and combined supplementation with curcumin and quercetin on the protective capacity in rats. Probl. Nutr. 86(2): 14-22.

Bavacad N., Hemarati G., Atace S., Karampour N. (2019) Preparation and physicochemical characterization of topical quercetin loaded liposome. Ars. Pharm. 60(1): 41-46.

Belyaev G. M. (2010) Modern understanding of the pathogenesis of psoriatic arthropathy and the treatment of these patients. Dermatol. Venerol. 47(1): 7-30.

Chaves M.A., Filho P.L.O., Jange C.G., Sinigaglia-Coimbra R., Oliveira C.L.P., Pinho S.C. (2018) Structural Characterization of multilamellar liposomes coencapsulating curcumin and vitamin D3. Colloids Surf. Colloids Surf. A: Physicochem. Eng. Asp. 549: 112-121.

Chen W., Zou M., Ma X., Lu R., Ding T. (2019) Co-encapsulation of EGCG and quercetin in liposomales for antioxidant activity. J. Food Sci. 84(1): 111-120.

Cheng A.L., Hsu C.H., Lin J.K., Hsu M.M., Ho Y.F., Shen T.S., Ko J.Y., Lin J.T., Lin B.R., Ming-Shiang W. et al. (2001) Phase I clinical trial of curcumin, a chemopreventive agent, in patients with high-risk or pre-malignant lesions. Anticancer Res. 21(4B): 2895-2900.

Deryugina A.V., Koryagin A.S., Kopyilova S.V., Talamanova M.N. (2010) Methods of study stress and adaptive reactions of the body in terms of the blood system. Nizhniy Novgorod, Izd. Nizhegorodsk. Gosuniv.

Di Vincenzo A., Tana C., El Hadi H., Pagano C., Vettor R., Rossato M. (2019) Antioxidant, anti-Inflammatory, and metabolic properties of tocopherols and tocotrienols: clinical implications for vitamin $E$ supplementation in diabetic Kidney disease. Int. J. Mol. Sci. 20(20): 5101.

Dong L.Y., Chen F., Xu M., Yao L.P., Zhang Y.J., Zhuang Y. (2018) Quercetin attenuates myocardial ischemia-reperfusion injury via downregulation of the HMGB1-TLR4$N F-\kappa B$ signaling pathway. Am. J. Transl. Res. 10(5): 1273-1283.

Dubinina E.E., Burmistrov S.O., Hodov D.A., Porotov I.G. (1995) Oxidative modification of human blood serum proteins and method of its determination. Issues Med. Chem. 41: 24-26.

Eschenko N.D. (1982) Methods of biochemical studies (lipid and energy metabolism). Determination of ATP in tissues. Izd. Leningradsk. Univ.: 210-212.

Esteban E.G., Cozar-Bernal M.J., Rabasco Alvarez A.M., Gonzalez-RodrHguez M.L. (2018) A comparative study of 
stabilising effect and antioxidant activity of different antioxidants on levodopa-loaded liposomes. J. Microencapsul. 35(4): 357-371.

Farías J.G., Molina V.M., Carrasco R.A., Zepeda A.B., Figueroa E., Letelier P., Castillo R.L. (2017) Antioxidant therapeutic strategies for cardiovascular conditions associated with oxidative stress. Nutrients 9(9): 966.

Feng T., Lee R., Wei Y., Zhao L. (2017) Liposomal curcumin and its application in cancer. Int. J. Nanomed. 12: 6027-6044.

Gaman D.V., Kononenko N.N., Gubina-Vakulik G.I., Tyupka T.I., Volkovoy V.A. (2011) Features of the morphogenic ultrastructure of the myocardium in experimental myocardial ischemia. Ukr. Biopharm. J. 5: 16-20.

Grygorieva G.S., Krasnopolsky Y.M., Konachovich N.F., Pasychnikova N.V. (2017) Method of obtaining a pharmacologically active liposomal quercetin-containing product. US Patent 20170196808.

Gubareva E.A., Kade A.H., Pavlyuchenko I.I., Zingilevskiy K.B., Staritskiy A.G., Basov A.A. (2008) Dynamics of enzyme activity of erythrocytes antiradical protection in patients with acute myocardial infarction on the background of conservative treatment. Fundam. Res. 1: 103-104.

Ivanova N.V., Yarosheva N.A. (2008) Pathogenetic justification for the use of lipoflavone in patients with various forms of diabetic retinopathy. Klin. Farmakol. 12(2): 11-16.

Khalil M.I., Sulaiman S.A. (2010) The potential role of honey and its polyphenols in preventing heart diseases: a review. Afr. J. Tradit. Complement Altern. Med. 7(4): 315-321.

Kibanov G.I., Babenkova I.V., Tiselkin Y.O. (1988) Determination of total antioxidant activity in blood serum. Lab. Delo. 5: 59-62.

Korolyuk M.A., Ivanova L.I., Mayorova I.G., Tokarev V.E. (1988) Method to determine catalase activity. Lab. Delo. 1: $16-19$.

Lakhanpal P., Rai D.K. (2008) Role of quercetin in cardiovascular diseases. Internet J. Med. Update 3(1): 31-49.

Liu Y., Wu Y.-M., Zhang P.-Y. (2015) Protective effects of curcumin and quercetin during benzo(a)pyrene induced lung carcinogenesis in mice. Eur. Rev. Med. Pharmacol. Sci. 19(9): 1736-1743.

Liu H.T., Huang Y.C., Cheng S.B., Huang Y.T., Lin P.T. (2016) Effects of coenzyme Q10 supplementation on antioxidant capacity and inflammation in hepatocellular carcinoma patients after surgery: a randomized, placebo-controlled trial. Nutr. J. 15(1): 85.

Liu K., Chen H., You Q.S., Ye Q., Wang F., Wang S., Zhang S.L., Yu K.J., Lu Q. (2017) Curcumin attenuates myocardial ischemia-reperfusion injury. Oncotarget. 8(67): 112051-112050.

Lopera Y.E., Fantinelli J., González Arbeláez L.F., Rojano B., Ríos J.L., Schinella G., Mosca S. (2013) Antioxidant activity and cardioprotective effect of a nonalcoholic extract of vaccinium meridionale Swartz during Ischemia-reperfusion in rats. Evid. Based Complement Alternat. Med. 2013: 516727.
Lü J.M., Lin P.H., Yao Q., Chen C. (2010) Chemical and molecular mechanisms of antioxidants: experimental approaches and model systems. J. Cell Mol. Med. 14(4): 840-860.

Matyushin B.N., Loginov A.S., Tkachev V.D. (1991) Determination of the superoxide dismutase activity in puncture biopsy specimens of the liver in chronic liver diseases. Lab. Delo. 7: 16-19.

Melnyk M.I., Dryn D.O., Al Kury L.T., Zholos A.V., Soloviev A.I. (2018) Liposomal quercetin potentiates maxi-K channel openings in smooth muscles and restores its activity after oxidative stress. J. Liposome Res. 29(1): 94-101.

Middleton E.Jr., Kandaswami C., Theoharides T.C. (2000) The effects of plant flavonoids on mammalian cells: implications for inflammation, heart disease, and cancer. Pharmacol. Rev. 52(4): 673-751.

Mosovska S., Petakova P., Kalina K.M., Miculajova S. (2016) Antioxidant properties of curcuminoids isolated from Curcuma longa L. Acta Chimica Slovaca. 9(2): 130-135.

Nakusov T.T. (2010) The effect of quercetin and dihydroquercetin on free radical processes in different organs and tissues of rats with hypoxia [dissertation abstract]. Rostov-onDon.

Ng Z.Y., Wong J.Y., Panneerselvam J., Madheswaran T., Kumar P., Pillay V., Hsu A., Hansbro N., Bebawy M., Wark P. et al. (2018) Assesing the potential of liposomes loaded with curcumin as therapeutic intervention in asthma. Colloids Surf. B Biointerfaces 72(1): 51-59.

Orlova E.A., Lazarchuk O.A. (2010) Change of superoxide dismutase activity in tissues of rats of different age under the influence of parapharmaceutics «Vin-Vita». Ukr. J. Clin. Lab. Med. 5: 87-90.

Ozgen S., Kivilcim O., Selananoglu Z. (2016) Antioxidant activity of quercetin: a mechanistic review. Turk. J. Agric. Food Sci. Technol. 4(12): 1134-1138.

Pasyechnikova N.V., Gorshkova R.A., Gaidamaka T.B. (2005) Preliminary evaluation of anti-inflammatory action of the drug «Lipoflavon» in patients after extracapsular cataract extraction. Ophthalmol. J. 3: 13-18.

Pavlova E.A. (2016) Influence of antioxidant therapy on the state of free radical lipids oxidation during severe $\mathrm{CHF}$. Exp. Clin. Med. 2(71): 143-146.

Pavlova E.A. (2017) The influence of antioxidant therapy on lipid peroxidation and antioxidant protection in ischemic heart disease. Actual Probl. Transp. Med. 1(47): 154-157.

Ryabokon E.N., Hudyakova M.B., Cherepinskaya U.A. (2011) Contents of proinflammatory il48 in the oral liquid of the patients with periodontal disease in application of gel containing granules of quercetinum. Med. Today Tomorrow 3(52): 140-142.

Pylypenko D.M., Bezrukavii D.S., Krasnopolsky Y.M. (2018) Application of nanobiotechnological forms of curcumin. Bull. NTU "KhPI", Ser: New Solutions Mod. Technol. 9(1285): 218-229

Pylypenko D.M., Gorbach T.V., Katsai O.G., Grigoryeva A.S., Krasnopolsky Y.M. (2019a) A study of oxidative stress markers when using the liposomal antioxidant complex. Pharmakeftiki 31(1): 40-47. 
Pylypenko D., Prochorov V., Dudnichenko O., Krasnopolsky Y. (2019b) Nanobiotechnological obtaining of liposomal forms of antioxidant preparations based on bioflavonoids. Sci. J. ScienceRise Pharm. Sci. 6(22): 11-15.

Pylypenko D.M., Krasnopolsky Y.M. (2019) Extraction and purification of curcuminoids from Curcuma longa L. rhizome. Ukr. Biopharm. J. 4(61): 60-64.

Rachmani A.R., Alsahi M.A., Aly S.M., Kham M.A., Aldebasi Y.H. (2018) Role of curcumin in disease prevention and treatment. Adv. Biomed. Res. 7: 38.

Ranjan A.P., Mukerjee A., Helson L., Gupta R., Vishwanatha J.K. (2013) Efficacy of liposomal curcumin in a human pancreatic tumor xenograft model: inhibition of tumor growth and angiogenesis. Anticancer Res. 33(9): 3603-3609.

Ravichandiran V., Masilamani K., Senthilnathan B., Maheshwaran A., Wong T.W., Roy P. (2017) Quercetin-decorated curcumin liposome design for cancer therapy: in-vitro and in-vivo studies. Curr. Drug Deliv. 14(8): 1053-1059.

Riva A., Ronchi M., Petrangolini G., Bosisio S., Allegrini P. (2019) Improved oral absorption of quercetin from Quercetin Phytosome $\Re$, a new delivery system based on food grade lecithin. Eur. J. Drug Metab. Pharmacokinet. 44(2): 169-177.

Rodrigo R., Libuy M., Feliú F., Hasson D. (2013) Molecular basis of cardioprotective effect of antioxidant vitamins in myocardial infarction. Biomed. Res. Int. 2013: 437613.

Romuk E., Jachec W., Kozielska-Nowalsky E., Burkner E. (2019) Superoxide dismutase activity as a predictor of adverse outcomes in patients with nonischemic diated cardiomyopathy. Cell Stress Chaperones 24(3): 661-673.

Sadeghi Ghadi Z., Dinarvand R., Asemi N., Talebpour Amiri F., Ebrahimnejad P. (2019) Preparation, characterization and in vivo evaluation of novel hyaluronan containing niosomes tailored by Box-Behnken design to co-encapsulate curcumin and quercetin. Eur. J. Pharm. Sci. 130: 234-246.

Sanmukhani J., Satodia V., Trivedi, J., Patel T., Tiwari D., Panchal B., Goel A., Tripathi C. B. (2014) Efficacy and safety of curcumin in major depressive disorder: a randomized controlled trial. Phytother. Res. 28(4): 579-585.

Shaji J., Iyer S. (2012) Preparation, optimization and in-vivo hepatoprotective evaluation of quercetin liposomes. Int. J. Curr. Pharm. Res. 4(2): 24-32.

Shakhmaiev A.E., Gorbach T.V., Bobritskaya L.A., Krasnopolsky Y.M. (2015) Preparation and cardioprotective effect analysis of liposomal coenzyme $Q_{10}$. Pharma Innovation 4(9): 22-26.
Shimatsu A., Kakeya H., Imaizumi A., Morimoto T., Kanai M., Maeda S. (2012) Clinical application of "curcumin", a multi-functional substance. Anti-Aging Med. 9(1): 43-51.

Shvets V.I., Krasnopolsky Y.M., Sorokoumova G.M. (2016) Liposomal forms of pharmaceutical preparations: technological features of production and use in the clinic. Moscow: Remedium.

Slesarchuk V.Y. (2014) The neuroprotective properties of Quercetin containing preparations. Pharmacol. Drug Toxicol. 6(41): 11-18.

Small G.W., Siddarth P., Li Z., Miller K.J., Ercoli L., Emerson N.D., Martinez J., Wong K.P., Liu J., Merrill D.A., Chen S.T., Henning S.M., Satyamurthy N., Huang S.C., Heber D., Barrio J.R. (2018) Memory and brain amyloid and Tau effects of a bioavailable form of curcumin in non-demented adults: a double-blind, placebo-controlled 18-month trial. Am. J. Geriatr. Psychiatry 26(3): 266-277.

Sotnikova O.P., Chudniavtseva N.O., Fesiunova H.S., Rodina Y.M., Lotosh T.D., Abramova A.B., Tsybuliak H.M. (2018) Effectiveness of the combined use of liposomal form of quercetin and aqueous extract of common melilot in moderate eye injury in rabbits. J. Ophthalmology. 6: 59-64.

State Pharmacopoeia of Ukraine. Vol. 1. (2015). Kharkiv: State-owned enterprise Ukrainian scientific pharmacopoeial center for quality of medicines.

Takahama H., Minamino T., Asanuma H., Fujita M., Asai T., Wakeno M., Sasaki H., Kikuchi H., Hashimoto K., Oku N., Asakura M., Kim J., Takashima S., Komamura K., Sugimachi M., Mochizuki N., Kitakaze M. (2009) Prolonged targeting of ischemic/reperfused myocardium by liposomal adenosine augments cardioprotection in rats. J. Am. Coll. Cardiol. 53(8): 709-717.

Tiano L., Belardinelli S., Carnevali R., Principi F., Seddaiu G., Littaru G.P. (2007) Effect of coenzyme Q10 administration on endothelial function and - extracellular superoxide dismutase in patients with ischaemic heart disease: a double - bind, randomized controlled study. Eur. Heart J. 28: 2249-2255.

Xu D., Hu M.J., Wang Y.Q., Cui Y.L. (2019) Antioxidant activities of quercetin and its complexes for medicinal application. Molecules 24(6): 1123.

Zhang L.K, Wang X.Z., Li W.S., Qiu X.J., Sun W., Hu G.-X. (2011) Pharmacokinetics and absolute bioavailability of curcumin in rats. Chin. Pharmacol. Bull. 27(10): 1458-1462. 